\title{
Geotechnological methods of gas extraction from technogenic coal deposits
}

\author{
Eduard Kliuiev ${ }^{1, *}$, Iryna Sapunova ${ }^{1}$, and Valerii Ivanov ${ }^{1}$ \\ ${ }^{1}$ Institute of Geotechnical Mechanics named by N. Poljakov of National Academy of Sciences of \\ Ukraine, 49005, Dnipro, Simferopolska Str., 2a, Ukraine
}

\begin{abstract}
The article presents an analysis of modern geotechnological methods of gas extraction from coal technogenic deposits. Special attention was focused to surface methods complex resource development, which concentrated in filled rock dumps and sludge accumulators of coalprocessing factories. The work describes physical-and-chemical methods of thermal impact on solid carbon-contained raw materials, which is considered as a binary mixture of coal and rock, in an oxygen-free medium or with the use of oxidants. The article presented the researches results of catalytic transformations taking place in the structure of a coal substance. Various versions of the use of catalysts in the processes of physical and chemical transformations of coal were proposed. The conducted researches allow to analyze the existing methods of impact on the mine medium identify the most perspective directions for the development of new methods in the field of geotechnological processes of gas extraction from coal technogenic deposits.
\end{abstract}

\section{Introduction}

The sustainable functioning of the fuel and energy complex of Ukraine is based on significant reserves of carbon-contained energy raw materials. In such a way, in order to increase gas production, it is necessary to develop new and improve existing geotechnological methods of coal deposit's development that would meet the modern achievements of science and technology, and would be economically beneficial and environmentally friendly. In some cases, the use of geotechnologies is the only possible way to transfer the mineral to a mobile state at the place of occurrence with subsequent release through wells to the surface. The use of geotechnologies ensures complete mechanization and automation of technological operations, contributes to the rapid deposit development, improving working conditions and a high degree of extraction of useful components.

With modern volumes of hydrocarbon consumption, it became necessary to obtain additional amounts of combustible gases by expanding the area of using thermal effects on the mine medium.

\footnotetext{
*Corresponding author: eduard.igtmnanu@gmail.com
} 


\section{The problem formulation}

It is common knowledge that one of the most perspective and up-to-date ways for obtaining of substitute of natural gas (methane) from coal and coal-contained material is the thermal impact in oxygen-free medium. Peat, lignite, bituminous shale were used often in such processes. High-ash coals and wash slurry wastes begin to use as a feedstock in thermal processing $[1,2]$. Intensive investigations in this field of study predetermined by the undoubted advantages, such us low pressure, absence of oxidizing reagents or catalysts, simplicity of process organization and low capital intensity.

The goal of the study is to produce further information regarding the following question: what technology should be applied to obtain more combustable gas for further commercial application.

The development and improvement of geotechnological methods for the gas extraction from solid carbon-contained raw materials are actively carried out both in Ukraine and abroad.

The analysis of existing works has shown that thermal impact on the mountain environment can take place both in an oxygen-free environment and with the use of oxidizers. These processes are characterized, first of all, by the decomposition of the organic matter, the recombination of the splitting products and the formation of thermodynamically stable final substances: the solid residue, the liquid products and the gas phase. The physical essence of the thermal impact process of coal and coal-contained materials is as follows. According to the Fuks-Krevelen pyrolysis theory [3] with a sufficient degree of accuracy it can be described as a chain of chemical reactions, involving the decomposition of organic matter occurred in the adjacent layer and in the outer surface of the particles.

Physical-chemical transformations begin to appear at temperatures of about $450 \mathrm{~K}$. However, at $350 \mathrm{~K}$ constitution moisture and adsorbed carbon gases, such us carbon dioxide, methane, air component were released. Thus, there is no decomposition of the organic matter, but probably occurs some certain changes in its internal structure.

At temperatures greater than $450 \mathrm{~K}$ a certain quantity of water vapor and carbon dioxide are evolved, that is a result of complicated chemical reactions, involving, in general, in the external polar groups.

In the temperature range of 500-600 K processes of coal structure decomposition are increased. The intensive emission of water vapor, carbon dioxide, some amounts of hydrogen sulfide and organic compounds of sulfur are occurred. At this stage, the oxygen content in the coal-contained material is markedly reduced. However, in this temperature range weak chemical bonds are splitting. Profound changes in the internal structure of the organic matter have not been observed yet.

At temperatures above $600 \mathrm{~K}$ the organic matter are intensively decomposed with the formation of free and unstable substance groups. Occurred recombination processes were developed in two directions: formation of condensed products characterized by a high content of carbon and low content of hydrogen; formation of liquid and gaseous products enriched with hydrogen.

Deep decomposition of organic matter and emission of liquid products are completed generally at a temperature of about $800 \mathrm{~K}$. These processes are accompanied by releasing of hydrogen, methane, carbon monoxide and nitrogen.

During further temperature heating the yield of methane, nitrogen, oxygen, carbon dioxide were not observed, however, the hydrogen and carbon monoxide were formed in significant quantities. In many coal-mining countries, various technological schemes are implemented, mainly aimed at obtaining synthetic liquid fuels and energy solid residue [46]. In conclusion, it is necessary to identify the following options of thermal impact: 
- low-temperature thermal impact (600-800 K), at which the maximum yield of the liquid phase and the solid residue, as well as the minimum yield of the gas phase with high calorific value;

- medium-temperature thermal impact $(800-1000 \mathrm{~K})$, in which there is an increase in the yield of the gas phase with a decrease in its heat of combustion and a decrease in the yield of liquid products and solid residue;

- high-temperature thermal impact (1000-1300 K), at which the yield of liquid and solid products reaches a minimum, and the output of the gas phase with a low calorific value is maximum.

\section{Results and discussion}

The existing technology of underground gasification of coal seams provides for the drilling of vertical, inclined and inclined-horizontal wells located at a distance of 20-36 m and combined along the coal seam with connections, to supply the blast and remove combustion products. At the same time, the coal seam gradually burns out from the bottom up, as the seam gas evaporates, the burnt out space is filled with collapsed roof rocks and ash residue of coal. The gas produced by means of air blast is used as fuel in the household sector. A technology for the extraction of methane has been proposed, which includes thermal and mechanical impact on the coal and rock massif through horizontal wells, due to which the gas permeability coefficient increases in 100-1000 times. To do this, vertically inclined wells are drilled on the coal seam and firing expansion of the drilling channels is used by moving the combustion center towards the injected air. As a result, gas with the high concentration of methane (up to $95 \%$ ) and the large expected flow rate, is expected to be used in power plants. The technology has a number of specific features [5]:

- the dependence of the process on the deposits' mining and geological conditions (lateral rocks play the role of the walls of a physical-and-chemical reactor, at a small depth they will not provide sufficient tightness of the underground gas generator);

- lack of fuel movement (the resulting gas moves together with the combustion zone and the firing face);

- the flow of catalytic processes (in the combustion zone there may be rocks, which include some chemical substances that contribute to a more rapid and efficient flow of physical and chemical transformations);

- penetration of groundwater into the gas generator (depending on different conditions, may lead either to stopping the process due to quenching of the coal seam, or to increasing the efficiency, since gasification would take place in the presence of water vapor).

The disadvantages of underground gasification of coal seams include: difficulties in managing and controlling the process, subsidence of the surface, which may lead to gas breakthrough during depressurization of pipelines and equipment; disruption of aquifers and possible pollution of groundwater; in the case of gas with low calorific value, it is unprofitable to transport it over long distances.

The integrated development of resources concentrated in the filled waste dumps and wash slurry wastes storage of coal preparation plants has a particular interest. The refining processes of such technogenic deposits are carried out in different ways, and the raw materials for them are different in size, physical, chemical and technological properties of coals.

Thus, in [7-8], an energy technological complex for processing coal waste using thermal impact was described. Coal waste from the accumulator enters the reactor, where it is continuously heated at temperatures of 500-900 K in an oxygen-free medium. In this case, chemicals in the presence of a heated solid residue, participating as a catalyst, are converted into a gas phase in an amount of $300 \mathrm{~m}^{3} / \mathrm{t}$, after which they are subjected to cooling and 
condensation. Uncondensed gas with a calorific value of more than $30 \mathrm{MJ} / \mathrm{kg}$ is characterized by the following composition (\% vol.): $\mathrm{CO}_{2}-1.5-2.5, \mathrm{CO}-11-18, \mathrm{H}_{2}-12-28$, $\mathrm{CH}_{4}-33-45, \mathrm{C}_{2} \mathrm{H}_{6}-19-20$, and is suitable for combustion in the boiler. The main disadvantages of this solution are related to the complexity of the thermal impact organization and its effective management. Also it should be mentioned the lack of data about the material composition and physical properties of raw materials, on which the quantity and chemical composition of the final products directly depend.

Under action of thermal impact in oxidizing medium, in which oxygen, water vapor, carbon dioxide, air, or their mixtures can be used, the organic part of unconditioned coal feedstock is directly converted into a gas phase, which mainly consists of monoxide and carbon dioxide, hydrogen, methane water vapor and nitrogen. Various technologies of thermal impact in oxidizing medium have been investigated, the most of them have special titles, such us Lurgi (stationary layer of lump coal), Winkler (fluidized bed), KoppersTotzek (pulverized coal vortex) and Texaco (water coal suspension) technologies [2-7].

The work [7] presents the results of the development and implementation of the processing of brown coal in a layered gasifier with the production of solid residue and combustible gas. It is based on the technological process of heat processing of coal, in which the volatile components of coal are gasified using the non-stationary effect of the "heat wave". The maximum temperature in the reaction zone is 1123-1173 K. The pilot tests conducted from the 1 ton of brown coal and produced $1700 \mathrm{~m}^{3}$ of combustible gas with a calorific value of 3.6-3.8 $\mathrm{MJ} / \mathrm{m}^{3}$. According to the energy balance, $56 \%$ of the combustion heat of the original coal is contained in the solid residue and $40 \%$ in the combustible gas. Compared with the existing industrialized solutions, the above-mentioned gas phase production process has a number of advantages: environmental safety (specific emissions of nitrogen, sulfur and dust oxides into the atmosphere are two orders of magnitude lower than that of coal-fired thermal power plants); due to the low filtration rate of gases in the reactor, the process is little dependent on the fractional composition, the hydraulic resistance of the layer and allows the processing of fine-grained coals; the absence of removal of fly ash from the layer (gas without purification can be used to produce electricity and / or heat energy); the discharge of the gaseous coolant into the atmosphere is absent and, therefore, the construction of additional gas cleaning and catalytic afterburning systems is not required; water is not used to extinguish the solid residue and condensation of decomposition products is not performed, therefore, there is no process waste water containing hazardous substances.

Many experiments, dedicated to thermal impact on substandard coal of the Lviv-Volyn basin in both air and water-air blast at a temperature of 1300-1400 K and atmospheric pressure [9], were conducted at a bench installation at the Institute of Geology and Geochemistry of Combustible Minerals of the National Academy of Sciences of Ukraine. The results analysis have shown that due to the heating of coal during impact, vapors of tar, pitcher water and combustible gas with a calorific value of $6-10 \mathrm{MJ} / \mathrm{m}^{3}$ and the following composition (\% vol.) were observed: $\mathrm{N}_{2}-3-7, \mathrm{O}_{2}-0.2-1.0, \mathrm{CO}_{2}-4-10, \mathrm{CO}-43-64, \mathrm{H}_{2}-$ $26-40, \mathrm{CH}_{4}-1.01-1.18, \mathrm{C}_{2} \mathrm{H}_{6}-0.03-0.13$. In the case of the use of heterogeneous lumpy coal after the completion of the experiment, it was noted that not all of the coal was subjected to thermal and oxidative effects. Some channels have formed in the layer, through which the oxidizing agent passed without entering into a chemical reaction. The disadvantages of technological solutions for the use of thermal impact for the production of combustible gases with oxidizing agents include: the complexity of the process organizatione; supply a significant amount of heat to maintain constant heating; the inability to obtain high-calorific gas due to the use of oxidizing agents that increase the amount of gas ballast components; additional costs for the production and storage of oxygen. 
The analysis have shown that the high ash and significant sulfur content in some grades of coal and rock are positive factors, if we consider them from the standpoint of some modern coal processing technologies based on the heat treatment process to produce gas. Consequently, the existing processes of thermal effects on solid carbon-contained raw materials are characterized by a significant decrease in the number of combustible components in the gas phase, significant environmental pollution and difficulties in controlling the process.

Recently, much attention has been paid to the development of fundamentally new, unconventional approaches, the distinguishing feature of which is not only the improvement of technological schemes, but also the acceleration of physical-and-chemical transformations of the components by means of catalysts. The implementation of thermal impact in the presence of catalysts helps to optimize the composition of the gas phase, to minimize the consumption of oxidizing agents and increase the speed and specific productivity of the process without increasing the temperature. Two main methods are applicable. One of them includes the direct interaction of the catalyst and the coal substance at the interface of their phases. Another group of methods differs in that catalytic transformations occur by the mechanism of "indirect" catalysis by transferring the action of the catalyst through the liquid or gaseous components of the reaction medium [11-13]. It has been established that the best contact is achieved by introducing a catalyst by chemical bonding with reactive functional groups on the surface of the coal, incorporating the coal into the bulk of the substance, as well as using catalysts in a dissolved, molten or volatile state. The high efficiency of the process can be achieved by using mechanical mixtures of crushed or diluted in a liquid medium of a solid catalyst and coal, as well as a stationary or fluidized bed of catalyst particles.

The temperature reducing helps to decrease the requirements for structural materials and avoids the use of expensive oxygen blast required to achieve high temperatures. The catalyst also contributes to a more intensive course of the methanation reaction. The introduction of potassium salts made it possible to increase the productivity of the reaction volume by $65 \%$ and reduce the cost of gases by $15 \%$.

Metal oxides as a catalysts is considered to be promised in heat treatment processes. So, due to the catalytic action of potassium, the process is carried out at a temperature of $1000 \mathrm{~K}$ instead of $1300-1900 \mathrm{~K}$ in traditional processes. At $1000-1300 \mathrm{~K}$, the rate of physical-and-chemical transformations of lignite is increased by two orders of magnitude when using a nickel catalyst. Its disadvantage is deactivation in the presence of sulfur and the need to use a relatively high concentration of nickel (from a few percent by weight of coal).

However, the use of a catalytic effect in the physical-and-chemical transformations of a coal substance is associated with the problem of developing simple and reliable methods for introducing a catalyst into the reaction mixture and regenerating it for reuse. As catalytically active materials, it was possible to use cheap and affordable metallurgical and boiler slags, accelerating the oxidation, methanation and conversion of coal. It was found that in the process of gasification in a fluidized bed of open-hearth slag, the conversion of coal increases from 40 to $76 \%$. The use of a circulating layer leads to an even greater catalytic effect, which makes it possible to maintain a high degree of coal conversion with an increase in the flow rate of the reaction mixture by a factor of 2.3 and to increase the productivity of the gas generator.

Thus, studies have shown that the efficiency of the processes of physical and chemical transformations of coal into environmentally friendly gaseous fuels can significantly increase with the use of appropriate catalysts, which allow reducing the temperature while maintaining a high process rate and adjust the composition of products. In many cases, it is economically and technically possible to use cheap disposable catalysts. 
In such a way, to verify a possibility of physical and chemical transformations acceleration, a dynamic model of the thermal impact on solid carbon-contained raw materials, taking into account heat exchange with limited air access was improved by the scientists of Institute of Geotechnical Mechanics named by N. Poljakov of National Academy of Sciences of Ukraine.

It was assumed that exothermic reactions occur at a certain speed in a mine medium with a porosity $K_{p}$, a bulk density $\gamma$, a heat capacity $C_{p}$, an ash content $A$, a moisture $W$ and a specific heat of combustion $Q$. In the simulation, the elemental volume of a cylindrical "chemical reactor" with diameter $d$, in which physical and chemical transformations took place, was considered. In this case, "reactor" is thermally insulated and the temperature of its walls is equal to the initial temperature of the mine medium $T_{0}$. The value of the kinetic constants of the process was taken from literary sources.

This mathematical model differs from the existing ones by allowing to determine the temperature distribution under action of thermal impact on the raw material, consisting of coal and rock, and to take into account the porosity of the mine medium ronment. Thus, the mathematical model describes the process of physical and chemical transformations in time on the basis of the next differential equations of thermal and material balance of the thermal action, and the equation that correlates the change of solid particles amount and residual air:

$$
\left\{\begin{array}{l}
\frac{\mathrm{d} \theta(\sigma)}{\mathrm{d} \sigma}=\bar{C}(\sigma) \cdot \bar{\mu}(\sigma) \cdot \frac{e^{-1 / \theta}}{\theta^{2}}-\Omega \cdot\left(\theta(\sigma)-\theta_{\mathrm{o}}\right) \\
K_{p} \cdot \frac{\mathrm{d} \bar{\mu}(\sigma)}{\mathrm{d} \sigma}=-\frac{1}{\theta_{\mathrm{ad}}} \cdot \bar{C}(\sigma) \cdot \bar{\mu}(\sigma) \cdot \frac{e^{-1 / \theta}}{\theta^{2}} \\
\bar{C}(\sigma)=1-\left(\frac{1-\bar{\mu}(\sigma)}{\alpha}\right)
\end{array}\right.
$$

Initial conditions: $\sigma=0 ; \theta=\theta_{0} ; \bar{\mu}=1$.

Value of dimensionless parameters:

$$
\begin{gathered}
\theta=\frac{R T}{E} ; \quad \sigma=\frac{273^{2} R^{3} Q \beta C_{0} \mu_{0} f k_{0}}{C_{\Sigma} E^{3}} \tau ; \quad \Omega=\frac{4 \alpha_{\mathrm{w}} E^{3}}{273^{2} R^{3} Q \beta C_{0} \mu_{0} f k_{0} d} ; \theta_{\mathrm{ad}}=\frac{Q \beta C_{0} R}{C_{\Sigma} E} ; \\
\bar{C}=\frac{C}{C_{0}} ; \bar{\mu}=\frac{\mu}{\mu_{0}},
\end{gathered}
$$

where $\theta$ - dimensionless process temperature; $\sigma$ - dimensionless process time; $\Omega$ dimensionless heat transfer coefficient; $\theta_{\mathrm{ad}}$ - dimensionless increase in temperature; $\bar{C}, \bar{\mu}-$ dimensionless values of the air amount and solid particles under normal physical conditions in the reaction zone, respectively; $K_{p}$ - porosity; $\alpha$ - coefficient of excess air; $R=8.31 \mathrm{~J} /(\mathrm{mol} \cdot \mathrm{K})$ - universal gas constant; $T$ - current process temperature, $\mathrm{K} ; \tau$ current time, s; $E$ - energy activation process, $\mathrm{J} / \mathrm{mol} ; Q$ - specific combustion heat of raw materials, $\mathrm{J} / \mathrm{kg} ; \beta$ - stoichiometric coefficient, which shows the ratio of the number of reacted particles to the amount of used air, $\mathrm{kg} / \mathrm{kg} ; C_{0}, \mu_{0}-$ initial quantities of air and particles under normal physical conditions, $\mathrm{kg} / \mathrm{m}^{3} ; f$ - total particle surface area per $1 \mathrm{~kg}$ of fuel, $\mathrm{m}^{2} / \mathrm{kg} ; k_{0}$ - constant value, which is determined from the Arrhenius equation, $\mathrm{m} / \mathrm{s} ; C_{\Sigma}$ - the heat capacity of air and solid particles under normal physical conditions, $J /\left(\mathrm{m}^{3} \cdot \mathrm{K}\right)$; $\alpha_{\mathrm{w}}$ - coefficient of heat transfer, $\mathrm{W} / \mathrm{m}^{2} ; d$-diameter of "chemical reactor", $\mathrm{m}$. 
However, due to the presence of a function $f(\theta)=\frac{1}{\theta^{2}} e^{-\frac{1}{\theta}}$ from the Arrhenius equation, the search for system solutions (1) with nonlinear differential equations is a complex problem. Therefore, the following method was used to solve it: firstly, the temperature range of the thermal impact, the dimensionless heat transfer coefficient $\Omega$ and the dimensionless temperature of the process $\theta_{0}$ were determined. Then, using the approximation method, the nonlinear function was represented as a polynomial of the second degree:

$$
f(\theta)=\frac{1}{\theta^{2}} e^{-\frac{1}{\theta}} \approx a_{2} \cdot \theta^{2}+a_{1} \cdot \theta+a_{0}
$$

where $a_{0}, a_{1}, a_{2}$ - approximation coefficients.

Using the method of variables separating, a solution in dimensionless form was obtained. In this case, the solution depends on the constant value $D^{*}=\left(a_{1}-\Omega\right)^{2}-4 a_{2}\left(a_{0}+\Omega \theta_{0}\right)$, and there are three possible cases:

- when $D^{*}>0$ one can get

$$
\sigma=\frac{1}{a_{i n}^{*}} \ln \left|\frac{2 a_{2} \theta+a_{1}-\Omega-a_{i n}^{*}}{2 a_{2} \theta+a_{1}-\Omega+a_{i n}^{*}}\right|+c_{1},
$$

where $a_{i n}^{*}=\sqrt{a_{1}^{2}-4 a_{0} a_{2}-2 a_{1} \Omega-4 a_{2} \theta_{0} \Omega+\Omega^{2}}-$ constant, which depends on initial conditions; $c_{1}=-\frac{1}{a_{i n}^{*}} \ln \left|\frac{2 a_{2} \theta_{0}+a_{1}-\Omega-a_{i n}^{*}}{2 a_{2} \theta_{0}+a_{1}-\Omega+a_{i n}^{*}}\right|-$ integration constant, which is determined from the initial conditions;

- when $D^{*}<0$ one can get

$$
\sigma=\frac{2}{a^{*}} \operatorname{arctg}\left(\frac{2 a_{2} \theta+a_{1}-\Omega}{a^{*}}\right)+c_{2} .
$$

where $a^{*}=\sqrt{4 a_{0} a_{2}-a_{1}^{2}+2 a_{1} \Omega+4 a_{2} \theta_{0} \Omega-\Omega^{2}}$ - constant, which depends on initial conditions; $c_{2}=-\frac{2}{a^{*}} \operatorname{arctg}\left(\frac{2 a_{2} \theta_{0}+a_{1}-\Omega}{a^{*}}\right)-$ integration constant, which is determined from the initial conditions;

- when $D^{*}=0$ one can get

$$
\sigma=-\frac{2}{2 a_{2} \theta+a_{1}-\Omega}+c_{3} .
$$

where $c_{3}=\frac{2}{2 a_{2} \theta_{0}+a_{1}-\Omega}-$ integration constant, which is determined from the initial conditions.

Graphs of dimensionless temperature growth, depending on the above conditions, are presented in Figures 1, 2. Based on the obtained results, the development of the process is 
characterized by a sharp rise in temperature curves, which indicates the beginning of intensive process of the medium heating. The time of the heat intensification beginning was determined by the size of the dimensionless time when a sharp increase of temperature occurs.

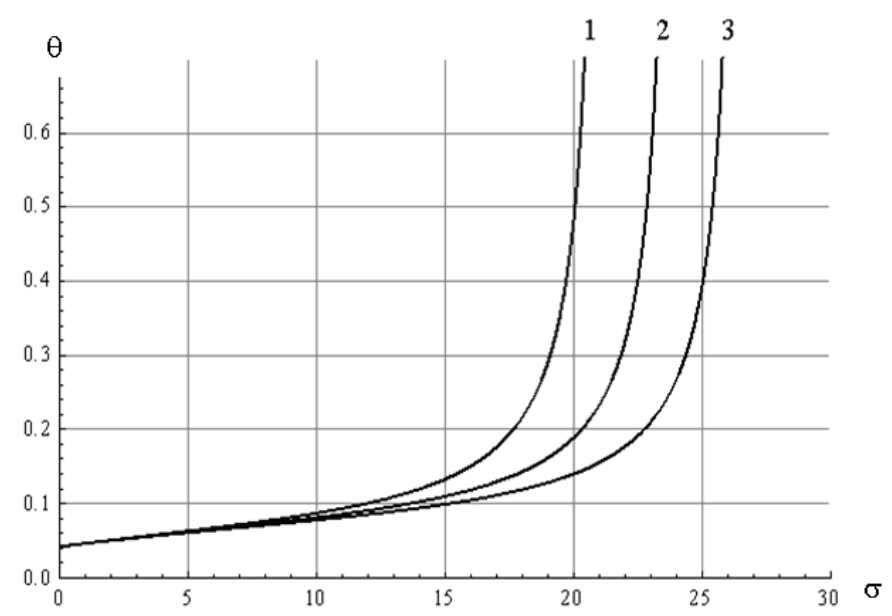

Fig. 1. The dependence of dimensionless temperature on the dimensionless time of the thermal impact in different heat transfer coefficient when the temperature range changes from $300 \mathrm{~K}$ to $1400 \mathrm{~K}$; $a_{0}=2.97 ; a_{1}=-0.34 ; a_{2}=0.009, K_{p}=0.3, E=49.9 \mathrm{~kJ} / \mathrm{mol}: 1-\Omega=0 ; 2-\Omega=0.02 ; 3-\Omega=0.04$.

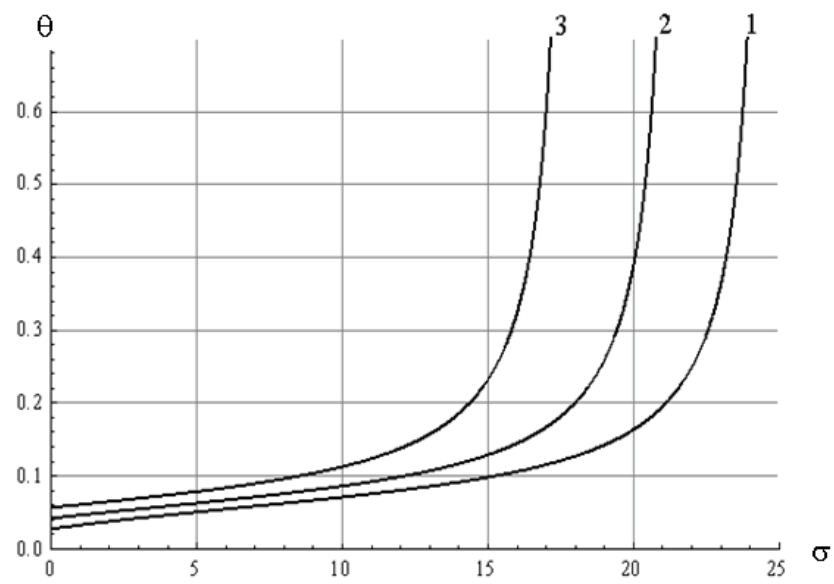

Fig. 2. The dependence of dimensionless temperature on the dimensionless time of the thermal impact at different initial temperature when the temperature range changes from $300 \mathrm{~K}$ to $1400 \mathrm{~K}$; $\Omega=0.02 ; a_{0}=2.97 ; a_{1}=-0.34 ; a_{2}=0.009, K_{p}=0.3, E=49.9 \mathrm{~kJ} / \mathrm{mol}: 1-T_{0}=300 \mathrm{~K}, 2-T_{0}=$ $600 \mathrm{~K}, 3-T_{0}=800 \mathrm{~K}$.

The obtained results allowed to understand that at a certain time an acceleration of physical and chemical processes was observed, indicating the possible occurrence of catalytic processes in the mine medium.

So, according to above mentioned information, it is necessary to propose a new beneficial way, which was developed and can be used for the thermal processing of carboncontained materials for the production of industrial gases [14].

The basis of the beneficial model is the task of improving the method of thermal processing of coals and wash slurry wastes, in which thermal processes are carried out with 
the allocation of the necessary gas phase, taking into account the material composition of carbon-contained materials and temperature. As a result, it will provide separate enterprises with the necessary volumes of gaseous fuel.

The method of thermal impact on coal-contained materials for obtaining industrial gases includes technological processes for the processing of coal-bearing materials under thermal action on them, with the release of the gas phase. The processing of materials, containing wash slurry wastes, sapropelite coal and their mixtures are carried out taking into account the weight material composition and temperature regime from 900 to $1100 \mathrm{~K}$. The specific yield of the gas phase $V_{s} \mathrm{~m}^{3} / \mathrm{t}$, depends on heating temperature $T, \mathrm{~K}$ is calculated by the formula $V_{s}=0.3922 \cdot T-131.02$.

It's really need to emphasize that under action of thermal impact action on a mixture of sapropelite and wash slurry wastes, taken in a weight ratio of $2: 1$, synthesis gas is obtained in the amount of $60 \%$ of the specific yield of the gas phase, with the specific energy costs of $2700 \mathrm{kWh} / \mathrm{t}$. When the heat is applied to a mixture of sapropelite and wash slurry wastes, taken in a weight ratio of $1: 1$, hydrogen is obtained in the amount of $47 \%$ of the specific yield of the gas phase, with the specific energy costs is equal $2800 \mathrm{kWh} / \mathrm{t}$. When thermal action on wash slurry wastes, methane is obtained in the amount of $30 \%$ of the specific yield of the gas phase, with the specific energy costs is equal $2500 \mathrm{kWh} / \mathrm{t}$.

The essence of the beneficial model is explained by the drawing (Fig. 3), which shows the layout of equipment placement during the implementation of the method.

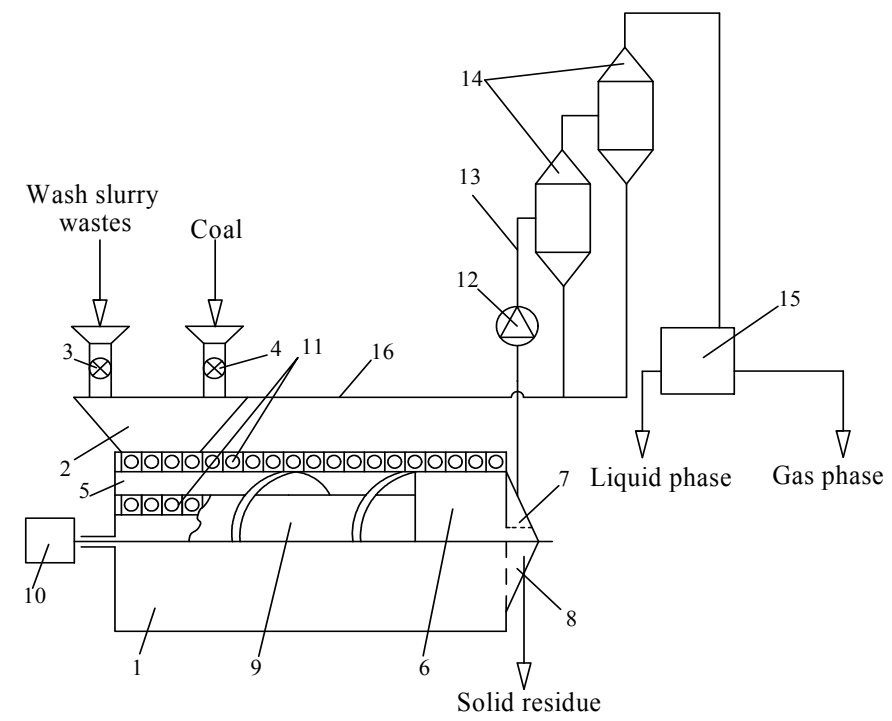

Fig. 3. Scheme of the method for thermal impact on carbon-contained materials: 1 - reactor body, 2 - loading device, 3, 4 - wash slurry wastes and coal batchers respectively, 5 - transport chamber, 6 - pyrolysis chamber, 7 - gas chamber, 8 - swing hatch, 9 - screw with internal cavity, 10 - engine, 11 - thermal units, 12 - pump, 13 - gas pipeline, 14 - cyclones, 15 - cooling chamber, 16 - pipeline for removal of solid residue.

Before loading coal-containing materials into reactor 1 , the loading device 2 is adjusted for a certain weight ratio of the mixture of sapropelite and wash slurry wastes by means of batchers 3, 4, depending on the final gas phase required for synthesis gas, hydrogen or methane.

The mixture enters the transport chamber 5 and the screw 9 is transferred it to the pyrolysis chamber 6 . During the transfer, the mixture undergoes thermal action from the thermal units 11 , which are located outside of the reactor body 1 and inside the screw 9 , 
which helps the mixture to quickly heat up in the pyrolysis chamber 6 , where the temperature reaches $1100 \mathrm{~K}$. The pyrolysis of the mixture with releasing of the gas phase into the gas chamber 7 occurs. From the chamber, the gas phase 7 is supplied by the pump 12 on the gas pipeline 13 to the cyclone 14, where it is cleared of solid impurities. Then it comes along the pipeline 16 in the loading device 2, preheating the materials, and the gas phase from the cyclones 14 enters the cooling chamber 15, from which it is selected for further processing to produce a final gas - synthesis gas, hydrogen or methane. All processes are carried out in an automatic mode, while the material in the pyrolysis chamber 6 is sealed under the action of the screw 9 and when a certain pressure is reached, the swing hatch 8 opens, releasing the chamber 6 from the slag residues, and the cycle repeats itself. The use of this method will significantly improve the quality of the joint processing of coals and wash slurry wastes, reduce energy costs, obtain synthesis gas, hydrogen and methane, which will provide individual enterprises with the necessary volumes of gaseous fuels.

\section{Conclusions}

As a result, there are several conclusions:

1. In modern conditions, in order to increase gas production, it is necessary to develop new and improve existing geotechnological methods of coal deposit development that would meet the modern development of science and technology, be economically viable and environmentally friendly.

2. The integrated development of resources concentrated in the filled waste dumps and wash slurry wastes storage of coal preparation plants has a particular interest. Depending on the temperature of the process of heat exposure on solid carbon-containing raw materials and the purpose of the products obtained, the following options are distinguished:

- at temperatures of $600-800 \mathrm{~K}$, the maximum yield of the liquid phase and the solid residue is achieved, as well as the minimum yield of the gas phase with a high calorific value;

- at temperatures of $800-1000 \mathrm{~K}$, an increase in the yield of the gas phase is observed with a decrease in its heat of combustion and a decrease in the yield of liquid products and a solid residue;

- at temperatures of 1000-1300 K, the yield of liquid and solid products reaches a minimum, and the output of the gas phase with a low calorific value is maximum.

3. The existing technology of underground gasification of coal seams is applicable in cases where the combustion process is easily controlled and controlled, and there will be no significant subsidence of the earth's surface without disturbing aquifers with minimal pollution of groundwater.

4. Under action of thermal impact in oxidizing medium, in which oxygen, water vapor, carbon dioxide, air, or their mixtures can be used, the organic part of carbon-contained raw material is directly converted into a gas phase, which mainly consists of monoxide and carbon dioxide, hydrogen, methane water vapor and nitrogen. Therefore, to obtain a gas phase with a high content of combustible components, it is recommended to use thermal effects on solid carbon-containing raw materials in an oxygen-free environment.

5. The use of the catalytic effect in the physicochemical transformations of a coal substance is associated with the problem of developing simple and reliable methods for introducing a catalyst into the reaction mixture and regenerating it for reuse. As catalytically active materials, it is possible to use cheap and affordable metallurgical and boiler slags, which accelerate the reactions of oxidation, methanation and conversion of coal. So, in the process of gasification in a fluidized bed of open-hearth slag, the conversion of coal increases by $30 \%$.

6. A new method for thermal impact on carbon-contained materials in order to obtain 
some industrial gases was developed by the scientists of Institute of Geotechnical Mechanics named by N. Poljakov of National Academy of Sciences of Ukraine. It is based on the phisical-and-chemical processes, taking into account the material composition and temperature.

\section{References}

1. Tabachenko, M.M., Vladyko, O.B., Homenko, O.Ye., Maltsev, D.V. (2012). Fizikohimichna geotehnologiya. Dnipropetrovsk: Nacionalnyu girnychyui universytet

2. Prihodchenko, V.L., Slashcheva, Ye.A., Osenniy, V.Ya., Koval, N.V., Kliuiev, E.S. (2010). The influence of heating conditions of low-grade coals and coal slimes on thermal degradation products, Geotekhnicheskaya Mekhanika [Geo-Technical Mechanics], 89, 65-72

3. Pomerantsev, V.V., Alfredov, K.M., Ahmedov, D.B. (1986). Osnovy prakticheskoy teorii goreniya. Leningrad: Energoatomizdat

4. Kreynin, Ye.V. (2004). Netraditsionnye termicheskiye technologii dobychy trudnoizvlekayemyh topliv: ugol, uglevodorodnoye syrye. Moskva: MGGU

5. Saranchuk, V.I., Ilyashov, M.O., Oshovskiy, V.V., BIletskiy, V.S. (2008). Osnovi himiy ta fiziki goryuchih kopalin. Donetsk: Shidnyi vydavnychiy dim

6. Falshtinskiy, V.S., Dychkovskiy, R.O., Stanchik, K., Svyadrovski, E., Lozinskiy, V.G. (2010). Justification of technological schemes of the experimental coal mine gas generator, Naukoviy visnik $N G U, 3,34-38$

7. P. Younger, Mine Water Environ, 30 (2011)

8. Kuznetsov, B.N. (1996). New approaches to chemical processing of fossil coals, Sorosovskiy obrazovatelnyi zhurnal, 6, 50-57

9. Bryk, D.V., Stefanyk, Yu.V. (2010). Gasification of low-grade coal of Lviv-Volyn basin, Uglehimicheskyi jurnal, 1-2, 20-32

10. Y. Sekine, K. Ishikawa, E. Kikuchi, M. Matsukata, A. Akimoto, Fuel, 85, 2 (2016)

11. K. Zubek, G. Czerski, S. Porada, Energy and fuels, 14 (2016)

12. Kusumano, D., Della-Beta, R., Levy, R. (1984). Kataliticheskiye protsessy pererabotki uglya. Moskva: Himiya

13. Orlova, V.M. (2005). The intensification of low-grade coal gasification of Ukraine using steel slags, Abstract of Ph.D. thesis, Chemical technology of fuel and fuel lubricants, Kharkiv

14. Bulat, A.F., Voziyanov, V.S., Kliuiev, E.S. (2015). Sposyb termichnoyi pererobky vuglevmisnyh materialiv dlya otrymannya promyslovyh gazyv. Patent No 98189, Ukraine 